\section{Population-level changes to promote cardiovascular health}

\author{
Torben Jørgensen 1,2,3, Simon Capewell ${ }^{4}$, Eva Prescott ${ }^{5}$, \\ Steven Allender ${ }^{6}$, Susana Sans ${ }^{7}$, Tomasz Zdrojewski ${ }^{8}$, Dirk De \\ Bacquer', Johan de Sutter', Oscar H Franco ${ }^{10,11}$, \\ Susanne Løgstrup ${ }^{12}$, Massimo Volpe ${ }^{13,14}$, Sofie Malyutina ${ }^{15}$, \\ Pedro Marques-Vidal ${ }^{16}$, Željko Reiner ${ }^{17}$, Grethe S Tell ${ }^{18}$, \\ WM Monique Verschuren ${ }^{19}$ and Diego Vanuzzo ${ }^{20}$ (on behalf of \\ the PEP section of the EACPR)
}

European Journal of Preventive Cardiology 20(3) 409-42

(C) The European Society of Cardiology 2012

Reprints and permissions: sagepub.co.uk/journalsPermissions.nav DOI: I0.1 I77/20474873 I244I 726 ejpc.sagepub.com

(S)AGE

\begin{abstract}
Background: Cardiovascular diseases (CVD) cause 1.8 million premature $(<75$ years) death annually in Europe. The majority of these deaths are preventable with the most efficient and cost-effective approach being on the population level. The aim of this position paper is to assist authorities in selecting the most adequate management strategies to prevent CVD.

Design and Methods: Experts reviewed and summarized the published evidence on the major modifiable CVD risk factors: food, physical inactivity, smoking, and alcohol. Population-based preventive strategies focus on fiscal measures (e.g. taxation), national and regional policies (e.g. smoke-free legislation), and environmental changes (e.g. availability of alcohol).

Results: Food is a complex area, but several strategies can be effective in increasing fruit and vegetables and lowering intake of salt, saturated fat, trans-fats, and free sugars. Tobacco and alcohol can be regulated mainly by fiscal measures and national policies, but local availability also plays a role. Changes in national policies and the built environment will integrate physical activity into daily life.

Conclusion: Societal changes and commercial influences have led to the present unhealthy environment, in which default option in life style increases CVD risk. A challenge for both central and local authorities is, therefore, to ensure healthier defaults. This position paper summarizes the evidence and recommends a number of structural strategies at international, national, and regional levels that in combination can substantially reduce CVD.
\end{abstract}

\title{
Keywords
}

Cardiovascular, health promotion, population, prevention, public health, structural strategies

Received I3 October 20II; accepted I3 February 2012

\footnotetext{
'Research Centre for Prevention and Health, Capital Region of Denmark, Denmark

${ }^{2}$ University of Copenhagen, Copenhagen, Denmark

${ }^{3}$ University of Aalborg, Aalborg, Denmark

${ }^{4}$ University of Liverpool, Liverpool, UK

${ }^{5}$ Bispebjerg University Hospital, Capital Region of Denmark, Denmark

${ }^{6}$ University of Oxford, Oxford, UK

${ }^{7}$ Institute for Health Studies, Barcelona, Spain

${ }^{8}$ Medical University of Gdansk, Poland

${ }^{9}$ Ghent University, Ghent, Belgium

${ }^{10}$ University of Cambridge, Cambridge, UK

"Erasmus University, Rotterdam, The Netherlands

${ }^{12}$ European Heart Network, Brussels, Belgium

${ }^{13}$ University Sapienza, Sant'Andrea Hospital, Rome
}

\footnotetext{
${ }^{14}$ IRCCS Neuromed, Pozzilli, Italy

${ }^{15}$ Siberian Branch of the Russian Academy of Medical Sciences, Novosibirsk, Russia

${ }^{16}$ Lausanne University Hospital, Lausanne, Switzerland

${ }^{17}$ University of Zagreb, Zagreb, Croatia

${ }^{18}$ University of Bergen, Bergen, Norway

${ }^{19}$ National Institute for Public Health and the Environment, Bilthoven, The Netherlands

${ }^{20}$ Medio Friuli, Udine, Italy

Corresponding author:

Torben Jørgensen, Research Centre for Prevention and Health, Capital Region of Denmark, Denmark

Email: torjor0I@regionh.dk
} 


\section{Introduction}

This position paper summarizes the available evidence of the effect of population level changes on risk factors for cardiovascular diseases (CVD). Our aim is to assist national authorities in selecting the most adequate management strategy to prevent CVD. The recommendations address the established risk factors for CVD, and will be valid for some other non-communicable diseases sharing the same risk factors, particularly type 2 diabetes, lung diseases, and common cancers. ${ }^{1}$ The evidence for changes in risk factors on a population level is based on best available scientific evidence. Recommendations for individual prevention approaches are given elsewhere. ${ }^{2,3}$

\section{The burden of CVD}

CVD remain the main cause of death in Europe leading to more than 4.3 million deaths in 2005 - every second death. ${ }^{4}$ Over $40 \%$ are premature, occurring before the age of 75 years ( 1.8 million), and $54 \%$ occur in women. Coronary heart disease (CHD) and stroke are the commonest forms of CVD constituting 22\% (1.9 million) and 14\% (1.2 million) of all deaths, respectively. CHD is responsible for $20 \%$ of all deaths before age 75 .

CVD mortality rates have decreased steadily in the European Union (EU) since the 1980s, and in Central Europe since the 1990s. ${ }^{5,6}$ A worrying upward pattern seen in Commonwealth of Independent States (CIS) has recently changed into a decline, but still there is a huge variation in CVD mortality across Europe (Figure 1). Disabilityadjusted life years (DALYs) provide an aggregate of years lost due to premature death and years of healthy life lost due to disability, and in 2005 CVD accounted for 34 million DALYs (23\% of total). ${ }^{5}$ Age-adjusted DALYs in Eastern Europe were three times higher than in Southern Europe.

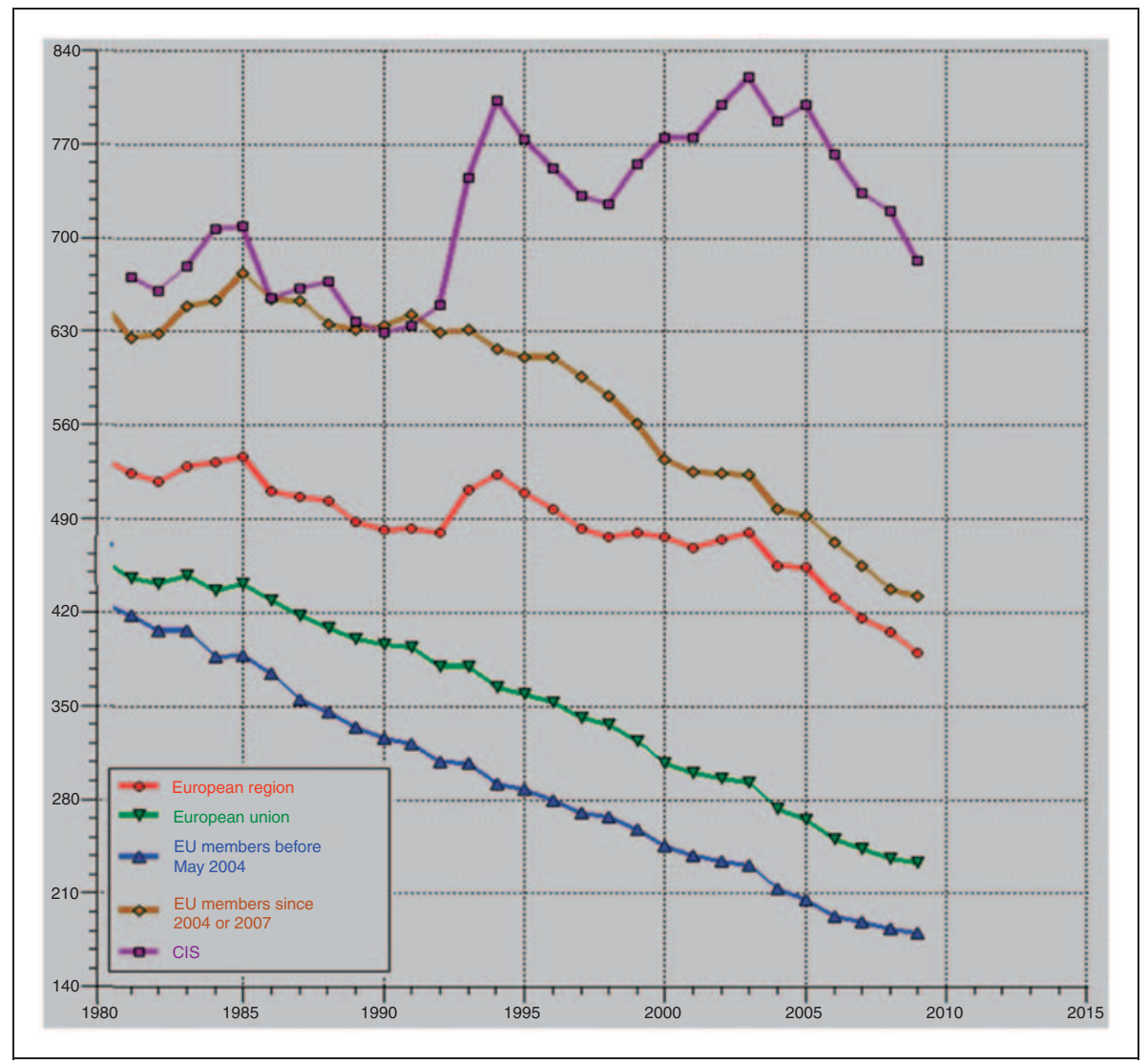

Figure I. Age- and sex-adjusted mortality rates (per 100,000) from CVD in Europe in the years 1980-2009. The European region includes all European countries including the CIS countries. The CIS countries comprises: Armenia, Azerbaijan, Belarus, Kazakhstan, Kyrgyzstan, Republic of Moldova, Russian Federation, Turkmenistan, Tajikistan, Ukraine (still not an official member), and Uzbekistan. Source: World Health Organization. ${ }^{6}$ 
Unlike mortality trends, hospital discharge rates for CVD (acute coronary syndromes and stroke) have increased in the majority of European countries. Recently this has tended to stabilize in EU, but increased rampantly in CIS (Figure 2). CVD hospital discharge rates in Lithuania are fivefold higher than in Cyprus. Overall CHD hospital discharges are increasing in Europe due to the more recent EU member countries and CIS. Other forms of CVD (including heart failure) account for more than half of hospital discharges in the majority of European countries. The changing and diverse CVD patterns are in line with observed changes of life style factors dealt with in the present $_{\text {paper. }}{ }^{7-10}$

In 2006, total CVD costs in EU exceeded 190 billion Euros, including 110 billion Euros for health care (54\% to inpatient care, $28 \%$ to medications, and $18 \%$ other). This represents an average expenditure of 223 Euros per capita per annum or $10 \%$ of total health care costs - ranging from 5\% in Cyprus, Denmark, and Luxemburg to $17 \%$ in Poland. ${ }^{11}$

\section{Risk factors}

Since the 1960s, multiple risk factors for CVD have been identified. ${ }^{2,5}$ Seven major modifiable risk factors tobacco, high blood pressure, high cholesterol, alcohol, low fruit and vegetable intake, physical inactivity, high blood pressure, high cholesterol, and obesity - account for over $60 \%$ of total DALYs in Europe. ${ }^{5}$ As high cholesterol, blood pressure, and obesity are strictly linked to unhealthy diet and physical inactivity, the present position paper will focus on diet, smoking, physical inactivity, and alcohol, which all can be modified through population-based strategies.

Healthy diets are characterized by high intakes of fruits, vegetables, legumes, fibre, whole grains, nuts,

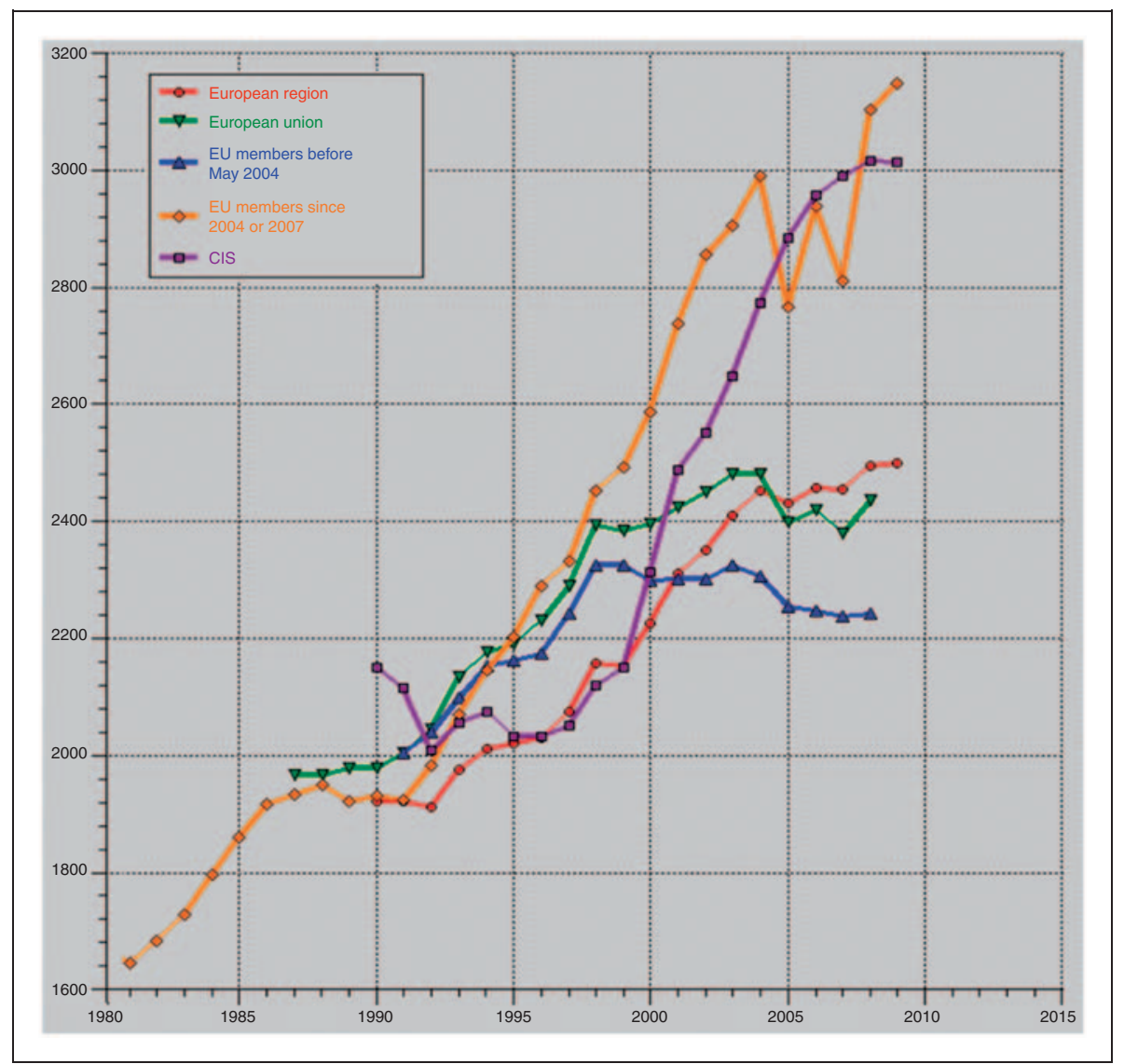

Figure 2. Age- and sex-adjusted hospital discharge rates (per 100,000) for CVD in Europe in the years 1980-2009. The European region includes all European countries including the Commonwealth of Independent States (CIS) countries. The CIS countries comprises: Armenia, Azerbaijan, Belarus, Kazakhstan, Kyrgyzstan, Republic of Moldova, Russian Federation, Turkmenistan, Tajikistan, Ukraine (still not an official member), and Uzbekistan. Source: World Health Organization. ${ }^{6}$ 
vegetable oils, and fish; whereas unhealthy diets are characterized by high intakes of salt, red meat, processed meat, saturated fat, trans-fat, refined grains, and refined sugars. Unhealthy diets greatly increase CVD incidence and premature mortality. ${ }^{3}$ Key problems are high salt intake, ${ }^{12}$ sugar sweetened beverages, and saturated fat, ${ }^{13-15}$ each accounting for $10-15 \%$ of calories consumed by youth. ${ }^{16}$ Smoking and passive smoking are among the best-established risk factors for CVD and premature mortality. ${ }^{2}$ Physical inactivity increases CVD and all-cause mortality. ${ }^{2,17}$ Recently even low-level physical activity has been shown beneficial for health, ${ }^{18}$ making 'sedentarism' (e.g. TV viewing, $\mathrm{PC}$ using) an independent risk factor. ${ }^{19,20}$ Both old and new media and systems of communication promote more sedentary habits and, frequently, imply higher consumption of snacks and junk food. Excess alcohol consumption is a risk factor for CVD. ${ }^{21}$ Light alcohol consumption may be protective, ${ }^{22}$ however, no controlled studies with sufficient long-term data exist, ${ }^{23}$ and there are concerns about publication bias in studies analysing lower levels of intake $(<50 \mathrm{~g} /$ day $){ }^{21}$

\section{Who is responsible? Prevention approaches and arenas}

Rose made the seminal argument for a focus on population level strategies for disease prevention. ${ }^{24} \mathrm{He}$ identified that a small shift in the risk of disease across a whole population can lead to greater reductions in disease burden than a large shift among those persons already at high risk. Thus greater health benefits can be achieved if preventive efforts are focused on the whole populations rather than mainly on high-risk individuals. Traditional approaches to epidemiology and individual interventions have produced major advances in elucidating the relationship between risk factors and disease outcomes. However, efficacious treatments at an individual level may flounder when scaled up beyond individual intervention to population-level efforts directed to several thousands of individuals. ${ }^{25}$

Socioecological theories have identified the relationships between different levels of determinants for chronic disease and consistently show that individual behaviour is nested within a number of other layers. CVD risk has, therefore, been variably depicted as the presence of lesions on an artery wall, blood levels of lipids, unhealthy diet and low physical activity, exposure to unhealthy food environments, dangerous neighbourhoods for active transport and urban planning, poverty, state and federal planning policy, and the implications of international trade agreements. These factors can be described as an axis of nested hierarchies from the micro level (e.g. individual choice, family influence) through the mezzo level (e.g. workplace, health care) and macro level (e.g. policy at state, city, or regional level) to global level (e.g. national policies and implications of international trade). ${ }^{26}$

While the personalized strategies will focus on the micro level, the population-based preventive strategies should focus on mezzo, macro, and global levels. Population-based strategies include fiscal measures (i.e. taxation and subsidies), international, national, and regional policy and legislation (e.g. smoke-free policies, rules for marketing, food production), and environmental changes. All strategies for changing risk factors, therefore, need to consider the interaction between levels and how policy change at national level shifts individual risk behaviour. ${ }^{27,28}$

Several stakeholders at different levels are concerned for each of the factors addressed in this position paper:

- international level (WHO, WTO, EU)

- national level (government department, health authorities, health agencies, industries)

- regional level (relevant authorities, such as for traffic planning, schools, construction of public buildings).

Responsibility should be shared between politicians, administrative authorities, health professionals, and NGOs. They should scrutinize the balance between health and profit, and be aware of conflicts of interests with industries. ${ }^{29}$ Communication to the general public should thus be the responsibility of health authorities, not industry. ${ }^{30,31}$ Mass media campaigns and individualized interventions to change behaviour can improve health, but are more likely to be effective if complementary policy or legal frameworks are in place making the healthy choices the easy choices. ${ }^{32}$ The diffusion of internet networks may obviously represent an opportunity.

\section{Recommendations and actions}

\section{Food}

Changing dietary patterns from unhealthy to healthy and lowering daily total energy intake will substantially lower cardiovascular risk. ${ }^{4,33,34}$ Diet is a very complex area in the cross field between personal choices, production, and marketing. Healthy food policies should aim to facilitate and incentivize positive interactions between governments, industry, and wider society to collaborate in achieving substantial reductions in CVD.

\section{International level}

WHO recommends salt intake to be less than $5 \mathrm{~g} /$ day, both saturated fat and free sugar to comprise less than $10 \%$ of total energy, and elimination of 
industrially produced trans-fats (TFA). ${ }^{35,36}$ There is growing awareness of the potential benefits of policy intervention in the agricultural sector to influence agricultural production practice. ${ }^{37}$ EU Common Agricultural Policy (CAP) and food systems have supported unhealthy diets. Future CAP reforms should, therefore, include public health nutrition in its objectives, e.g. by supporting a shift from meat and dairy products to fruit and vegetables. ${ }^{38-40}$

\section{National level}

Pricing. Taxation of unhealthy food is estimated to reduce CVD death in UK by perhaps $2 \%{ }^{41}$ Taxation of sugar, fat, and salty foods are implemented in some countries. ${ }^{34}$ In the USA, soda taxes are implemented in 14 states. ${ }^{14}$ No substantial knowledge of the effect on consumption or obesity exist, ${ }^{42}$ but tax is often lowered due to lobbying from industries. ${ }^{43}$

Subsidies for fruit and vegetables increase affordability. ${ }^{44}$ The EU school fruit scheme has been widely adopted, with some benefit. ${ }^{45}$ Agricultural subsidies have been successful in Finland helping farmers to make substantial shifts from meat and dairy to oil, seed, and berry production. ${ }^{46,47}$

Restriction/availability. Several countries have developed guidelines to reduce salt to below $6 \mathrm{~g} / \mathrm{day},{ }^{12}$ though relatively few have gone beyond policy statements. ${ }^{48}$ Eighty percent of salt intake stems from the processed food industry ${ }^{12}$ and increasing successes have followed pressure on food industry and governments. ${ }^{49}$ Legislative measures were effective in reducing salt in Finland (from 14 to $9 \mathrm{~g} /$ day), and other countries have followed. ${ }^{50}$ In contrast, voluntary agreements involving collaboration with food companies have achieved smaller reductions, e.g. UK (from 9.5 to $8.6 \mathrm{~g} /$ day). ${ }^{4}$ Modelling studies in USA, ${ }^{51} \mathrm{UK}^{52}$ and Australia ${ }^{53}$ have consistently suggested that salt reduction is powerful and cost-saving. Legislation for salt reduction may be 20 times more effective than voluntary schemes. ${ }^{53}$

Legislation to remove industrial trans-fatty acid (TFAs) has been successfully implemented in Denmark, Sweden, Iceland, Austria, Switzerland, Seattle, and New York. ${ }^{36}$ Voluntary schemes are reducing TFA intakes more slowly in UK and Netherlands. ${ }^{4,36}$ Data on the effect on CVD are awaited.

Advertising of junk food (food high in fat, salt, and sugar). Restriction may be very efficient. ${ }^{54,55}$ In the UK, the Office of Communication (OFCOM) banned any TV advertising of food high in fat, salt, and sugar (HFSS) aimed at children, where they make up more than $60 \%$ of the audience. ${ }^{54,56}$ Exposure fell by about one-third in $2007 / 08$ compared to 2005 . Data on actual changes in HFSS intake are needed. ${ }^{54,56}$

Labelling. This aims to increase consumer information, inform consumer choice, and pressure manufacturers to reformulate. Traffic light schemes are consistently effective and preferred by consumers in diverse jurisdictions across Europe, USA, and Australia. ${ }^{57,58}$ The UK Food Standards Agency recommended traffic lights, but industry lobbying resulted in a more complex hybrid scheme. In the Netherlands, a 'Healthy choice logo' for recommended 'basic' products and 'Conscious choice logo' for non-basic products was introduced. The Nordic Council of Ministers has endorsed a keyhole symbol indicating healthy food items. ${ }^{59}$ Additional data on the effect of labelling on changes in availability and in purchasing are needed.

\section{Regional level}

Restrictions/availability. Some countries have developed and promoted nutritional criteria for schools through government or local policies e.g. UK School Food Trust and Caroline Walker Trust. ${ }^{60}$ Vending machines for confectionery and soft drinks were seen in less than $5 \%$ in primary schools in Denmark ${ }^{61}$ Other countries are now banning such vending machines (France, UK, USA). Singapore regulated vending machines and gave access to water coolers resulting in decrease in obesity. ${ }^{62}$ It is important that schools avoid economic dependency on vending machines. HFSS food and snacks in schools also need control. ${ }^{45}$ Controlling the number of fast food restaurants near schools appears potentially useful. ${ }^{63} \mathrm{~A}$ borough in London (Barking and Dagenham) recently won a legal victory supporting a policy restricting takeaways near schools. Data on the effect of these regulations on HFSS intake among school children is needed. ${ }^{44}$

Healthy food initiatives in public and workplace canteens were started in the North Karelia program then rolled out across Finland. ${ }^{64}$ In 2008, Los Angeles banned new fast-food outlets to reduce obesity. The coverage of the ban was weak and there is uncertainty about any effect. ${ }^{65}$

\section{Smoking}

Any reduction in smoking and second-hand smoke exposure will lead to reduced cardiovascular morbidity and mortality. Although smoking prevalence is declining, the decline is less evident in lower socioeconomic groups and underreporting is increasing. ${ }^{66}$ There is no safe level of second-hand smoke exposure and a completely smoke-free environment is the only way to protect non-smokers. Voluntary policies, separate smoking 
rooms, and improved ventilation do not reduce secondhand exposure to an acceptable level. ${ }^{67,68}$

\section{International level}

The WHO Framework Convention on Tobacco Control (FCTC) has specified recommendations for the implementation of national, comprehensive smoke-free laws, currently adopted by more than 170 countries. ${ }^{69}$ However, in several countries legislation offers only limited protection or laws are not enforced. To avoid border sales, harmonization of excise duties at a high level within the EU should be pursued. ${ }^{70}$

\section{National level}

Pricing. For each $10 \%$ increase in retail prices, tobacco consumption is reduced by $4 \%$ in highincome and $8 \%$ in low- and middle-income countries. Teenagers and poor are more sensitive to increased taxation with 2-3-fold higher probability of quitting after price increases. ${ }^{71-73}$

Restrictions. Adolescents do not worry about health consequences of smoking and are more susceptible to peer pressure and advertising. Several studies with community-level intervention have shown that restrictions on adolescents' access to tobacco leads to reduced smoking prevalence. ${ }^{74-76}$ Restriction on retail aimed at youth would include banning of tobacco vending machines. Restrictions on retail sale for adults, as implemented in some countries for alcohol, have not been studied. Smoking bans in the public domain led to reduction in exposure to passive smoking and an estimated $17 \%$ reduction in incidence of myocardial infarction, ${ }^{77,78}$ while it is less clear whether legislation also leads to smoking cessation in the general population. ${ }^{79}$

Labeling. One of the best ways to raise awareness of the dangers of tobacco is through the adoption of large mandatory pictorial warnings on the pack. Although pictorial and text health warnings have been shown to increase perception of risk and to reduce smoking uptake, changes cannot be attributed to labelling alone. ${ }^{80}$ Health warnings have greater impact in countries with more comprehensive tobacco control programmes and in smokers with lower socioeconomic status. ${ }^{81}$ To enhance effectiveness of pictorial warnings, they must be combined with plain, standardized packaging. ${ }^{70,82-86}$

Advertising. Exposure to advertising is associated with increased likelihood that in particular adolescents will take up smoking. ${ }^{87}$ A complete ban of all advertising and marketing may lead to $7 \%$ reduction in tobacco consumption, whereas partial banning of advertising has little if any effect on smoking prevalence. ${ }^{88}$

Media campaigns. TV campaigns may reduce smoking uptake by teenagers and increase quit rates among adults. ${ }^{89,90}$ Based on few and heterogeneous studies, a Cochrane review concluded that mass media campaigns may have an effect on smoking behaviour in adults, ${ }^{91}$ whereas anti-tobacco campaigns directed at youth in schools have not reduced initiation. ${ }^{92,93}$

\section{Regional level}

Restriction. Smoking bans at workplaces have lead to reductions in exposure to passive smoking, in particular among hospitality workers, decreased cigarette consumption during the working day, and higher smoking cessation rates. ${ }^{94,95}$ Restrictions on smoking in general may enhance a cultural shift towards 'denormalization' of smoking, as a high public support for and compliance with smoking bans has been seen after passing legislation. ${ }^{79}$ Smoke-free policies at working sites can provide substantial saving to employers as well as health benefits for the former tobacco user ${ }^{95}$ without harming business in restaurants and bars. ${ }^{96-98}$

\section{Physical inactivity}

Any increase in daily physical activity and decrease in sedentary time will reduce CVD morbidity and mortality. ${ }^{18,99,100}$ Trends go towards integrating physical activity into daily life activities such as reducing sitting time $^{99}$ and promoting active commuting as cycling and walking to work. A simulation study showed that change in environment to support more active lifestyle was cost-effective. ${ }^{101}$ Public perception of the importance of physical activity is still relative low in some countries, e.g. Croatia. ${ }^{102}$

Reviews ${ }^{103,104}$ and reports ${ }^{105-107}$ have summarized the available evidence on how to promote and create built or natural environments that encourage and support physical activity. A recent Cochrane review ${ }^{108}$ concluded that there is a noticeable inconsistency of the findings of available studies and that there is a clear need for future well-designed intervention studies. The review mixes the effect of individualized intervention with mass campaigns and (seldom) structural changes, which makes it difficult to delimitate the effect of structural changes.

\section{International level}

Recommendations at population levels are to change environments that facilitate physical activities, which fit into daily routine making it easier for people to follow 
the current guidelines, which includes moderate-intensity activities (e.g. brisk walking) for a minimum of 30 minutes on 5 days/week or vigorous-intensity activities (e.g. jogging) for a minimum of 25 minutes on 3 days/ week, or a combination of both. ${ }^{109}$

\section{National and regional level}

Pricing. Taxing private motor transport with introduction or road-user charges and higher parking fees together with cheaper public transport can support physically active modes of transport. ${ }^{105}$

Restriction/availability. A re-allocation of road space by introducing cycle and footpath lanes, closing or narrowing roads in city, and creating or enhancing places for physical activity is beneficial. ${ }^{103}$

Linkage of different sites (e.g. homes, schools) by appropriate walking and cycling networks (trail connectivity) including safe routes to schools will facilitate walking and cycling. ${ }^{105,107}$ Use of staircases rather than elevators and escalators can be encouraged as default by good visibility and signposting. ${ }^{110}$ Designing school playgrounds so that they encourage varied physically active play combined with it being compulsory to be in the schoolyard during lesson breaks will facilitate physical activity. ${ }^{111}$

Encouragement of employees to walk, cycle, or use other modes of transport involving physical activity in travel to and from work and as part of their working day. ${ }^{106}$ Finally, introduction of systematic breaks in sitting time is a promising new effort. ${ }^{99,106}$

\section{Alcohol}

Although 'light-to-moderate' alcohol consumption may be beneficial in CVD prevention, the message is often interpreted inappropriately. Excessive alcohol intake is clearly associated with increased cardiovascular mortality $^{21}$ and alcohol ranks as the second-leading cause of DALYs lost in high-income countries. ${ }^{112}$ Recommending of alcohol consumption for nondrinking persons is therefore not supported.

\section{International level}

WHO and EU recommend taxation, low legal limits for alcohol concentrations in blood for drivers, minimum age for purchasing alcohol, and regulation of availability. ${ }^{30,113}$

\section{National level}

Pricing. A huge literature establishes that for each $10 \%$ increase in retail price, alcohol consumption is reduced by $5.1 \%$, ranging from $4.6 \%$ for beer to $8.0 \%$ for spirits. ${ }^{114}$

Restriction. Age limits for sale and serving with consequences for shops and restaurant that violate the rules are effective. ${ }^{115-117}$ Various drink-driving strategies are very effective in reducing numbers of persons driving after drinking alcohol, ${ }^{118,119}$ which may have an indirect effect on the overall consumption of alcohol. Government retail monopolies for sale of alcohol can reduce alcohol-related harm due to restriction in the number of outlets for alcohol purchase; furthermore reducing the hours of sale of alcohol has shown beneficial effect. ${ }^{120}$

Labelling. Labelling alcohol with information on caloric content and health warning messages of the harmful effects of alcohol has shown limited effect. ${ }^{121}$

Advertising. Alcohol advertising, promotion, and sponsorship of events is clearly related to initiation of young drinking, and it seems as if the effect of exposure is dose related and cumulative over time. ${ }^{116}$ This could support that banning alcohol advertising would be effective in reducing consumption.

Regional level. Alcohol regulations in policies on workplaces, educational centres, and schools are effective, whereas education of the harmful effect of alcohol in schools have no effect, ${ }^{116}$ which is the preferred recommendation of the alcohol industry. ${ }^{116}$

\section{Discussion}

Societal changes during the last decades have led to the present harmful environment with high calorie intake, low degree of physical activity, continuous smoking, and high alcohol intake. As systematic screening and multifactorial individualized intervention is insufficient in changing CVD risk at a population level, ${ }^{25}$ a structural approach is called for. This paper shows several initiatives at international, national, and regional levels that can contribute to reduction in CVD.

Besides strategies including taxation, subsidies, and statutory regulation, strategies such as 'nudging' and 'default' have been proposed as tools. ${ }^{122,123}$ Nudge to push mildly - can be done by setting the default to healthy. A default is an option that will be obtained if the chooser does nothing, so a large number of people will end up with that option, whether or not it is good for them. This is the way that advertising and space management in supermarkets work. Therefore, a task for both national and local authorities is to regulate society to the more healthy default. This was launched by WHO in 1986 - 'making the healthy choices the 
Box. Population level changes to prevent CVD: main conclusions and recommendations

- CVD causes more than 4.3 million annual death in Europe and costs at least 190 billion $€$.

- Important modifiable risk factors for CVD (unhealthy diet, smoking, alcohol, and physical inactivity) all respond to structural changes in society.

- Population level interventions aim at small changes in the whole population, which can have a higher impact on overall CVD burden than changes among high-risk individuals.

- Responsibility for structural changes should be shared between politicians, administrative authorities, and health professionals. Changes should be at international, national, and local levels.

- Healthy dietary habits will be supported by changes in agricultural policies, tax on products with free sugar and saturated fat and subsidies for fruit and vegetables, reduction of salt and trans-fatty acids in processed foods, clear labelling of foods, and limiting advertising for junk food.

- Completely smoke-free environments are the only way to protect non-smokers. Smoking and second-hand smoking can be regulated by taxation, restrictions in sale and use, banning advertising, plain packaging, and warning labels.

- Physical activities should be integrated in daily life by subsidies to public transport and re-allocating of road space to cycle and footpath lanes. Changes in schools, worksites, and built environment can make physical activity a more natural part of daily life.

- Alcohol intake can be reduced by taxation, low availability, regulation of advertising, and low social and legal tolerance of drink driving.

- It is estimated that such population-level changes can halve CVD mortality rates.

- In a complex, modern society there is an interaction between personal choices, production and marketing. To secure a real free choice for citizens, health authorities need to ensure healthy defaults, thus balancing the vested interests of corporations, who are not responsible for public health.

easy choices'. ${ }^{124}$ However, policies to promote healthy lifestyle routinely face opposition by commercial vested interest from corporations (e.g. food, tobacco, alcohol) and health authorities need to anticipate this conflict of interest in their attempt to change the CVD risk. $^{29,31,125,126}$

Opponents allege that the 'nanny state' hinders the free choice of people, ${ }^{122,127}$ but the fact is that people today are nudged in the wrong direction by corporations' de facto setting of the default option. ${ }^{123}$ Yet, corporations do not have responsibility for population health - this is the responsibility of governments, which have a duty of care, already acknowledged in respect to public health successes including clean water and air, sanitation, and traffic regulation. For example, reducing air pollution is a prioritized area in Europe with the 6th Environment Action Programme ${ }^{128,129}$ based on the Clean Air for Europe programme ${ }^{130}$ and the WHO guidelines for air quality. ${ }^{128}$ The average exposure index (AEI) of PM2.5 in European countries (2007) varies from about $10 \mathrm{yg} / \mathrm{m}^{3}$ in Ireland and Finland to above $30 \mu \mathrm{g} / \mathrm{m}^{3}$ in Bulgaria and Romania. ${ }^{131}$ Estimates show that with a reduction in PM2.5 to $6 \mathrm{yg} / \mathrm{m}^{3}$ mortality for cardiopulmonary diseases and lung cancer will be reduced by $17 \% .{ }^{132}$ Changes from private cars to public transport and better facilities for physical active modes of transport will both increase physical activity and reduce pollution.

It is only natural to extend these well-established responsibilities to create healthy societies. ${ }^{124}$ The freedom of choice will remain, so people still can make the unhealthy choices. But as most people want the healthy choice, a more healthy default will help in lowering the
CVD risk. New media, which can be used to promote unhealthy behaviours, could instead generate institutional strategies at national level to support healthier individual behaviours. ${ }^{133}$

Social inequality in health is increasing ${ }^{134}$ and is exacerbated by a predominant focus on individualized prevention. ${ }^{122}$ There is a concern about the impact of psychosocial factors including chronic stress and lack of social network influencing the burden of CVD, but the knowledge of which interventions are effective is sparse. ${ }^{135} \mathrm{WHO}$ recommends making social support in stress prevention an important goal for communities and managers. ${ }^{136}$ The structural changes mentioned in this presentation seem to have the potential to decrease social inequality in health. ${ }^{122}$

Population interventions tend to work quickly ${ }^{77,78}$ and to be cost saving. ${ }^{53,73,101}$ Structural changes to avoid chronic diseases are now favoured from several sides. ${ }^{137}$ The growing literature of the possible impact of structural strategies on health signals a paradigm shift in CVD prevention. Small changes in the whole society - changes that will not be dramatic for the single citizen - will substantially change the risk of CVD according to Rose's preventive paradox. ${ }^{24}$ A report from the National Institute of Clinical Excellence (NICE) have estimated that a UK national programme reducing population cardiovascular risk by $1 \%$ would prevent 25,000 CVD cases and generate savings of $€ 40$ million per annum. Reducing mean population cholesterol or blood pressure by $5 \%$ would result in annual savings exceeding $€ 100$ million. ${ }^{4}$ A WHO bulletin report suggests that CHD mortality rates easily could be halved by modest risk factor reduction ${ }^{138}$ and that 
improved diet alone could halve CVD death. ${ }^{34}$ The question has been raised whether structural changes with a slight reduction over the whole spectre of CVD risk is more efficient than a high-risk strategy using, for example, the polypill (consisting of cholesterol-lowering, antihypertensive, and antiplatelet agents). ${ }^{139-142}$ Adapting the polypill approach includes screening with detection of high-risk persons, initiation of treatment and compliance, which will never reach $100 \%$. And even if the $100 \%$ compliance was reached, it has been estimated that the population approach seems to be more effective. ${ }^{143}$ The polypill should be reserved for people at high risk if its efficacy and safety is demonstrated. In general, population-based and high-risk strategies should be used complementarily.

Much research needs to be done, but the structural strategies represent a powerful and cost-effective strategy, which so far has been underestimated.

\section{Funding}

This research received no specific grant from any funding agency in the public, commercial, or not-for-profit sectors.

\section{References}

1. Beaglehole R, Bonita R, Horton R, et al. Priority actions for the non-communicable disease crisis. Lancet 2011; 377(9775): 1438-1447.

2. Graham I, Atar D, Borch-Johnsen K, et al. European guidelines on cardiovascular disease prevention in clinical practice: executive summary. Fourth Joint Task Force of the European Society of Cardiology and other societies on cardiovascular disease prevention in clinical practice (constituted by representatives of nine societies and by invited experts). Eur J Cardiovasc Prev Rehabil 2007; 14(Suppl 2): E1-E40.

3. Reiner Z, Catapano AL, De Backer G, et al. ESC/EAS Guidelines for the management of dyslipidaemias: The Task Force for the management of dyslipidaemias of the European Society of Cardiology (ESC) and the European Atherosclerosis Society (EAS). Eur Heart J 2011; 32(14): 1769-1818.

4. National Institute for Health and Clinical Excellence. Prevention of cardiovascular disease at population level. London: NICE, 2010. NICE public health guidance 25.

5. World Health Organization. European health report. Health and health systems. Geneva: WHO, 2009.

6. World Health Organization. European Health for All database (HFA-DB). Geneva: WHO, 2011. Available at: http://data.euro.who.int/hfadb/ [consulted October 2011].

7. Bobak M, Murphy M, Rose R, et al. Societal characteristics and health in the former communist countries of Central and Eastern Europe and the former Soviet Union: a multilevel analysis. $J$ Epidemiol Community Health 2007; 61(11): 990-996.
8. Boylan S, Welch A, Pikhart H, et al. Dietary habits in three Central and Eastern European countries: the HAPIEE study. BMC Public Health 2009; 9: 439.

9. Bandosz P, O'Flaherty M, Drygas W, et al. Decline in mortality from coronary heart disease in Poland after socioeconomic transformation: Modelling study. BMJ 2012; 344: d8136.

10. Unal B, Critchley JA and Capewell S. Explaining the decline in coronary heart disease mortality in England and Wales between 1981 and 2000. Circulation 2004; 109(9): 1101-1107.

11. European Heart Network. European cardiovascular disease statistics 2008. Brussels: European Heart Network, 2010. Available at: www.ehnheart.org/cvd-statistics.html [consulted October 2011].

12. He FJ and MacGregor GA. A comprehensive review on salt and health and current experience of worldwide salt reduction programmes. J Hum Hypertens 2009; 23(6): 363-384.

13. Fung TT, Malik V, Rexrode KM, et al. Sweetened beverage consumption and risk of coronary heart disease in women. Am J Clin Nutr 2009; 89(4): 1037-1042.

14. Harris JL, Schwartz MB, Brownell KD, et al. Fast food facts: Evaluating fast food nutrition and marketing to youth. New Haven: Rudd Center for Food Policy and Obesity, 2010.

15. Malik VS, Popkin BM, Bray GA, et al. Sugar-sweetened beverages, obesity, type 2 diabetes mellitus, and cardiovascular disease risk. Circulation 2010; 121(11): 1356-1364.

16. Scottish Intercollegiate Guidelines Network. Risk estimation and the prevention of cardiovascular disease. Edinburgh: SIGN, 2007. National clinical guideline 97.

17. Nocon M, Hiemann T, Muller-Riemenschneider F, et al. Association of physical activity with all-cause and cardiovascular mortality: a systematic review and meta-analysis. Eur J Cardiovasc Prev Rehabil 2008; 15(3): 239-246.

18. Sattelmair J, Pertman J, Ding EL, et al. Dose response between physical activity and risk of coronary heart disease: a meta-analysis. Circulation 2011; 124(7): 789-795.

19. Frydenlund G, Jorgensen T, Toft U, et al. Sedentary leisure time behavior, snacking habits and cardiovascular biomarkers: the Inter99 Study. Eur J Cardiovasc Prev Rehabil 2011; August 22 [Epub ahead of print].

20. Grontved A and Hu FB. Television viewing and risk of type 2 diabetes, cardiovascular disease, and all-cause mortality: a meta-analysis. JAMA 2011; 305(23): 2448-2455.

21. Corrao G, Rubbiati L, Bagnardi V, et al. Alcohol and coronary heart disease: a meta-analysis. Addiction 2000; 95(10): 1505-1523.

22. Ronksley PE, Brien SE, Turner BJ, et al. Association of alcohol consumption with selected cardiovascular disease outcomes: a systematic review and meta-analysis. BMJ 2011; 342: d671.

23. Brien SE, Ronksley PE, Turner BJ, et al. Effect of alcohol consumption on biological markers associated with risk of coronary heart disease: systematic review and metaanalysis of interventional studies. BMJ 2011; 342: d636. 
24. Rose G. The strategy of preventive medicine. Oxford: Oxford University Press, 1992.

25. Ebrahim S, Taylor F, Ward K, et al. Multiple risk factor interventions for primary prevention of coronary heart disease. Cochrane Database Syst Rev 2011; (1): CD001561.

26. Glass TA and McAtee MJ. Behavioral science at the crossroads in public health: extending horizons, envisioning the future. Soc Sci Med 2006; 62(7): 1650-1671.

27. Greater than the sum: systems thinking in tobacco control. Rockville, Maryland: National Cancer Institute, US Department of Health and Human Services. National Institutes of Health, 2007.

28. Atella V, Brady A, Catapano AL, et al. Bridging science and health policy in cardiovascular disease: focus on lipid management: a report from a session held during the 7 th International Symposium on Multiple Risk Factors in Cardiovascular Diseases: Prevention and Intervention Health Policy, in Venice, Italy, 25 October, 2008. Atheroscler Suppl 2009; 10(1): 3-21.

29. Jahiel RI and Babor TF. Industrial epidemics, public health advocacy and the alcohol industry: lessons from other fields. Addiction 2007; 102(9): 1335-1339.

30. World Health Organization. WHO expert committee on problems related to alcohol consumption. Geneva: WHO, 2011.

31. Gilmore AB, Savell E and Collin J. Public health, corporations and the new responsibility deal: promoting partnerships with vectors of disease? J Public Health (Oxf) 2011; 33(1): 2-4.

32. Wakefield MA, Loken B and Hornik RC. Use of mass media campaigns to change health behaviour. Lancet 2010; 376(9748): 1261-1271.

33. Franco M, Ordunez P, Caballero B, et al. Impact of energy intake, physical activity, and population-wide weight loss on cardiovascular disease and diabetes mortality in Cuba, 1980-2005. Am J Epidemiol 2007; 166(12): 1374-1380.

34. Mozaffarian D and Capewell S. United Nations' dietary policies to prevent cardiovascular disease. BMJ 2011; 343: d5747.

35. World Health Organization. Diet, nutrition and the prevention of chronic diseases. Report of a Joint WHO/FAO Expert Consultation. Geneva: WHO, 2003.

36. National Heart Forum. Elimination of industrially produced trans fats (IPTFAs) from foods consumed in the UK. London: National Heart Forum, 2010.

37. Hawkes C. Promoting healthy diets and tackling obesity and diet-related chronic diseases: what are the agricultural policy levers? Food Nutr Bull 2007; 28(2 Suppl): S312-S322.

38. European Commission. The Common Agricultural Policy after 2013. Public debate, summary report. Brussels: European Commission, Agriculture and Rural Development, 2010.

39. European Heart Network. Diet, physical activity and cardiovascular disease prevention in Europe. Fighting heart disease and stroke. Brussels: European Heart Network, 2011.
40. Lock K and Pomerleau J (eds) Fruit and vegetable policy in the European Union: Its effect of the burden of cardiovascular disease. London: European Heart Network, 2005.

41. Mytton O, Gray A, Rayner M, et al. Could targeted food taxes improve health? J Epidemiol Community Health 2007; 61(8): 689-694.

42. Fletcher JM, Frisvold D and Tefft N. Taxing soft drinks and restricting access to vending machines to curb child obesity. Health Aff (Millwood) 2010; 29(5): 1059-1066.

43. Thow AM, Quested C, Juventin L, et al. Taxing soft drinks in the Pacific: implementation lessons for improving health. Health Promot Int 2011; 26(1): 55-64.

44. Sturm R and Datar A. Regional price differences and food consumption frequency among elementary school children. Public Health 2011; 125(3): 136-141.

45. Hawkes C. Regulating and litigating in the public interest: regulating food marketing to young people worldwide: trends and policy drivers. Am J Public Health 2007; 97(11): 1962-1973.

46. Photius Coutsoukis. Finland Agricultural Policy. Available at: http://www.photius.com/countries/finland/ economy/finland_economy_agricultural_policy.html [1988, consulted October 2011].

47. Laatikainen T, Critchley J, Vartiainen E, et al. Explaining the decline in coronary heart disease mortality in Finland between 1982 and 1997. Am J Epidemiol 2005; 162(8): 764-773.

48. Penney S. Dropping the salt. Practical steps countries are taking to prevent chronic non-communicable diseases through population-wide salt reduction. Washington, DC: Pan American Health Association, 2009.

49. World Action on Salt and Health. www.worldactiononsalt.com [2011, consulted October 2011].

50. He FJ and MacGregor GA. Reducing population salt intake worldwide: from evidence to implementation. Prog Cardiovasc Dis 2010; 52(5): 363-382.

51. Bibbins-Domingo K, Chertow GM, Coxson PG, et al. Projected effect of dietary salt reductions on future cardiovascular disease. N Engl J Med 2010; 362(7): 590-599.

52. Barton $\mathrm{P}$, Andronis L, Briggs A, et al. Effectiveness and cost effectiveness of cardiovascular disease prevention in whole populations: modelling study. BMJ 2011; 343: d4044.

53. Cobiac LJ, Vos T and Veerman JL. Cost-effectiveness of interventions to reduce dietary salt intake. Heart 2010; 96(23): 1920-1925.

54. Boyland EJ, Harrold JA, Kirkham TC, et al. The extent of food advertising to children on UK television in 2008. Int J Pediatr Obes 2011; 6(5-6): 455-461.

55. Linn SE. Food marketing to children in the context of a marketing maelstrom. J Public Health Policy 2004; 25(34): $367-378$.

56. Ofcom. HFSS advertising restrictions - final review. Available at: http://stakeholders.ofcom.org.uk/marketdata-research/tv-research/hfss-final-review/ [2010, consulted October 2011].

57. AgriQuality. On-going food label monitoring survey in Australia and New Zealand. Report on the re-assessment 
of 2003 labels for nutrition, health and related claims. Phase 2, Part C. Canberra: FSANZ, 2005.

58. European Heart Network. Food information to consumers. Brussels: European Heart Network, 2010. Available at: www.ehnheart.org/publications/positionpapers/publication/18-good-information-to-consumers. html [consulted October 2011].

59. Nordic Council of Ministers. About the keyhole. Copenhagen: Nordic Council of Ministers [2011]. Available at: http://www.norden.org/en/nordic-councilof-ministers/councils-of-ministers/council-of-ministersfor-fisheries-and-aquaculture-agriculture-food-and-forestry-mr-fjls/keyhole-nutrition-label/about-the-keyhole/ [consulted October 2011]

60. Nelson M, Nicholas J, Wood L, et al. Statistical release: take up of school lunches in England 2010-2011. Sheffield: School Food Trust, 2011.

61. Lissau I and Poulsen J. Nutrition policy, food and drinks at school and after school care. Int J Obes (Lond) 2005; 29(Suppl 2): S58-S61.

62. Toh CM, Cutter J and Chew SK. School based intervention has reduced obesity in Singapore. BMJ 2002; 324(7334): 427.

63. Larson NI, Story MT and Nelson MC. Neighborhood environments: disparities in access to healthy foods in the US. Am J Prev Med 2009; 36(1): 74-81.

64. Roos E, Sarlio-Lahteenkorva $\mathrm{S}$ and Lallukka T. Having lunch at a staff canteen is associated with recommended food habits. Public Health Nutr 2004; 7(1): 53-61.

65. Sturm R and Cohen DA. Zoning for health? The year-old ban on new fast-food restaurants in South LA. Health Aff (Millwood) 2009; 28(6): w1088-w1097.

66. Gallus S, Tramacere I, Boffetta $\mathrm{P}$, et al. Temporal changes of under-reporting of cigarette consumption in population-based studies. Tob Control 2011; 20(1): 34-39.

67. Health effects of exposure to environmental tobacco smoke. California Environmental Protection Agency. Tob Control 1997; 6(4): 346-353.

68. IARC Working Group on the Evaluation of Carcinogenic Risks to Humans. Tobacco smoke and involuntary smoking. IARC Monogr Eval Carcinog Risks Hum 2004; 83: 1-1438.

69. World Health Organization. Guidelines for implementation. Geneva: WHO Framework Convention on Tobacco Control, 2011. Articles 5.3, 8-14.

70. Smokefree Partnerships. Spotlight on the European Commission proposals to amend EU Directives on the rates and structure of taxes on manufactured tobacco. Brussels: Smokefree Partnerships, 2009. Available at: http://www.smokefreepartnership.eu/IMG/pdf/

Spotlight_4.pdf [consulted October 2011].

71. Centers for Disease Control and Prevention. Response to increases in cigarette prices by race/ethnicity, income, and age groups - United States, 1976-1993. MMWR Morb Mortal Wkly Rep 1998; 47(29): 605-609.

72. Ding A. Curbing adolescent smoking: a review of the effectiveness of various policies. Yale J Biol Med 2005; 78(1): $37-44$.
73. Jha $\mathrm{P}$ and Chaloupka FJ. The economics of global tobacco control. BMJ 2000; 321(7257): 358-361.

74. Chen V and Forster JL. The long-term effect of local policies to restrict retail sale of tobacco to youth. Nicotine Tob Res 2006; 8(3): 371-377.

75. Cummings KM, Hyland A, Perla J, et al. Is the prevalence of youth smoking affected by efforts to increase retailer compliance with a minors' access law? Nicotine Tob Res 2003; 5(4): 465-471.

76. Jason LA, Ji PY, Anes MD, et al. Active enforcement of cigarette control laws in the prevention of cigarette sales to minors. JAMA 1991; 266(22): 3159-3161.

77. Goodman PG, Haw S, Kabir Z, et al. Are there health benefits associated with comprehensive smoke-free laws. Int J Public Health 2009; 54(6): 367-378.

78. Lightwood JM and Glantz SA. Declines in acute myocardial infarction after smoke-free laws and individual risk attributable to secondhand smoke. Circulation 2009; 120(14): 1373-1379.

79. Callinan JE, Clarke A, Doherty K, et al. Legislative smoking bans for reducing secondhand smoke exposure, smoking prevalence and tobacco consumption. Cochrane Database Syst Rev 2010; (4): CD005992.

80. Hammond D. Health warning messages on tobacco products: a review. Tob Control 2011; 20(5): 327-337.

81. Hitchman SC, Mons U, Nagelhout GE, et al. Effectiveness of the European Union text-only cigarette health warnings: findings from four countries. Eur $J$ Public Health 2011 September 15 [Epub ahead of print].

82. Sambrook Research International. A review of the science base to support the development of health warnings for tobacco packages. Newport, UK: Sambrook Research International, 2009.

83. Hammond D, Fong GT, McDonald PW, et al. Impact of the graphic Canadian warning labels on adult smoking behaviour. Tob Control 2003; 12(4): 391-395.

84. Hammond D, Fong GT, McNeill A, et al. Effectiveness of cigarette warning labels in informing smokers about the risks of smoking: findings from the International Tobacco Control (ITC) Four Country Survey. Tob Control 2006; 15(Suppl 3): iii19-iii25.

85. Hammond D, Fong GT, McDonald PW, et al. Showing leads to doing: graphic cigarette warning labels are an effective public health policy. Eur J Public Health 2006; 16(2): 223-224.

86. White V, Webster B and Wakefield M. Do graphic health warning labels have an impact on adolescents' smokingrelated beliefs and behaviours? Addiction 2008; 103(9): 1562-1571.

87. Lovato C, Linn G, Stead LF, et al. Impact of tobacco advertising and promotion on increasing adolescent smoking behaviours. Cochrane Database Syst Rev 2003; (4): CD003439.

88. Saffer H and Chaloupka F. The effect of tobacco advertising bans on tobacco consumption. J Health Econ 2000; 19(6): 1117-1137.

89. McVey D and Stapleton J. Can anti-smoking television advertising affect smoking behaviour? controlled trial of the Health Education Authority for England's anti-smoking TV campaign. Tob Control 2000; 9(3): 273-282. 
90. Siegel $M$ and Biener L. The impact of an antismoking media campaign on progression to established smoking: results of a longitudinal youth study. Am J Public Health 2000; 90(3): 380-386.

91. Bala M, Stzeszynski L and Cahill K. Mass media interventions for smoking cessation in adults. Cochrane Database Syst Rev 2008; (1): CD004704.

92. Thomas R. School-based programmes for preventing smoking. Cochrane Database Syst Rev 2002; (4): CD001293.

93. Wiehe SE, Garrison MM, Christakis DA, et al. A systematic review of school-based smoking prevention trials with long-term follow-up. J Adolesc Health 2005; 36(3): $162-169$.

94. Fichtenberg CM and Glantz SA. Effect of smoke-free workplaces on smoking behaviour: systematic review. BMJ 2002; 325(7357): 188.

95. Hopkins DP, Razi S, Leeks KD, et al. Smokefree policies to reduce tobacco use. A systematic review. Am J Prev Med 2010; 38(2 Suppl): S275-S289.

96. Office of Tobacco Control. Smoke-free workplaces in Ireland: A one-year review. Naas: Office of Tobacco Control, 2005.

97. Binkin N, Perra A, Aprile V, et al. Effects of a generalised ban on smoking in bars and restaurants, Italy. Int $J$ Tuberc Lung Dis 2007; 11(5): 522-527.

98. Scollo M, Lal A, Hyland A, et al. Review of the quality of studies on the economic effects of smoke-free policies on the hospitality industry. Tob Control 2003; 12(1): 13-20.

99. Healy GN, Dunstan DW, Salmon J, et al. Breaks in sedentary time: beneficial associations with metabolic risk. Diabetes Care 2008; 31(4): 661-666.

100. O'Donovan G, Blazevich AJ, Boreham C, et al. The $\mathrm{ABC}$ of physical activity for health: a consensus statement from the British Association of Sport and Exercise Sciences. J Sports Sci 2010; 28(6): 573-591.

101. Roux L, Pratt M, Tengs TO, et al. Cost effectiveness of community-based physical activity interventions. Am J Prev Med 2008; 35(6): 578-588.

102. Reiner Z, Sonicki Z and Tedeschi-Reiner E. Public perceptions of cardiovascular risk factors in Croatia: the PERCRO survey. Prev Med 2010; 51(6): 494-496.

103. Kahn EB, Ramsey LT, Brownson RC, et al. The effectiveness of interventions to increase physical activity. A systematic review. Am J Prev Med 2002; 22(4 Suppl): 73-107.

104. Yang L, Sahlqvist S, McMinn A, et al. Interventions to promote cycling: systematic review. BMJ 2010; 341: c5293.

105. National Institute for Health and Clinical Excellence. Promoting and creating built or natural environments that encourage and support physical activity. London: NICE, 2008. Public health guidance 8.

106. National Institute for Health and Clinical Excellence. Workplace health promotion: how to encourage employees to be physically active. London: NICE, 2008. Public health guidance 13 .

107. National Institute for Health and Clinical Excellence. Promoting physical activity, active play and sport of pre-school and school-age children and young people in family, pre-school, school and community settings. London: NICE, 2009. Public health guidance 17.

108. Baker PR, Francis DP, Soares J, et al. Community wide interventions for increasing physical activity. Cochrane Database Syst Rev 2011; (4): CD008366.

109. World Health Organization. Global recommendations on physical activity for health. Geneva: WHO, 2010. Available at: http://www.who.int/dietphysicalactivity/ factsheet_recommendations/en/ [consulted October 2011].

110. Meyer P, Kayser B, Kossovsky MP, et al. Stairs instead of elevators at workplace: cardioprotective effects of a pragmatic intervention. Eur J Cardiovasc Prev Rehabil 2010; 17(5): 569-575.

111. Shape Up Europe. www.shapeupeurope.net [consulted October 2011].

112. World Health Organization. Global health risk: Mortality and burden of disease attributable to selected major risks. Geneva: WHO, 2009.

113. RAND Europe. First progress report on the implementation of the EU alcohol strategy. Brussels: European Commission, Directorate-General for Health and Consumers, 2009.

114. Wagenaar AC, Salois MJ and Komro KA. Effects of beverage alcohol price and tax levels on drinking: a meta-analysis of 1003 estimates from 112 studies. Addiction 2009; 104(2): 179-190.

115. National Institute for Health and Clinical Excellence. Alcohol-use disorders: preventing the development of hazardous and harmful drinking. London: NICE, 2010. Public health guidance 24.

116. Anderson P. Global alcohol policy and the alcohol industry. Curr Opin Psychiatry 2009; 22(3): 253-257.

117. Wagenaar AC and Toomey TL. Alcohol policy: gaps between legislative action and current research. Contemporary Drug Problems 2000; 27(4): 681-733.

118. Mann RE, Macdonald S, Stoduto LG, et al. The effects of introducing or lowering legal per se blood alcohol limits for driving: an international review. Accid Anal Prev 2001; 33(5): 569-583.

119. Shults RA, Elder RW, Sleet DA, et al. Reviews of evidence regarding interventions to reduce alcoholimpaired driving. Am J Prev Med 2001; 21(4 Suppl): 66-88.

120. Her M, Giesbrecht N, Room R, et al. Privatizing alcohol sales and alcohol consumption: evidence and implications. Addiction 1999; 94(8): 1125-1139.

121. Stockwell T. A review of research into the impacts of alcohol warning labels on attitudes and behaviour. British Colombia, Canada: Center for Addiction Research of BC, University of Victoria, 2006.

122. Capewell S and Graham H. Will cardiovascular disease prevention widen health inequalities? PLoS Med 2010; 7(8): e1000320.

123. Thaler RH and Sunstein CR. Nudge. Improving decisions about health, wealth, and happiness. London: Penguin Books, 2009.

124. WHO/HPR/HEP/95.1, editor. Ottawa Charter for Health Promotion. First International Conference on Health Promotion. Ottawa: WHO, 1986. 
125. Brownell KD and Warner KE. The perils of ignoring history: Big Tobacco played dirty and millions died How similar is Big Food? Milbank $Q$ 2009; 87(1): 259-294.

126. Wiist WH. The bottom line or public health. Tactics corporations use to influence health and health policy, and what we can do to counter them. Oxford: Oxford University Press, 2010.

127. Marteau TM, Ogilvie D, Roland M, et al. Judging nudging: can nudging improve population health? $B M J$ 2011; 342: d228.

128. World Health Organization. Air quality guidelines. Global update 2005. Geneva: WHO, 2006.

129. European Commission. CAFE reference documents. Brussels: European Commission, Environment. 2011. Available at: http://ec.europa.eu/environment/archives/ cafe/general/keydocs.htm [consulted October 2011].

130. European Commission. EU focus on clear air. Brussels: European Commission, 1999.

131. Matthijsen J JB, de Leeuw FAAM and Smeets W. Attainability of PM2.5 air quality standards, situation for the Netherlands in a European context. Netherlands Environmental Assessment Agency, 2009. BOP report.

132. Anenberg SC, Horowitz LW, Tong DQ, et al. An estimate of the global burden of anthropogenic ozone and fine particulate matter on premature human mortality using atmospheric modeling. Environ Health Perspect 2010; 118(9): 1189-1195.

133. Steele BN, Draney MT, Ku JP, et al. Internet-based system for simulation-based medical planning for cardiovascular disease. IEEE Trans Inf Technol Biomed 2003; 7(2): 123-129.

134. Marmot M. Fair society, healthy lives. The Marmot review. Executive Summary. London: UCL Institute of Health Equity, 2011.
135. Theorell T, Kristensen TS, Kornitzer M, et al. Stress and cardiovascular disease. In: Vicki J, RobertsGassier BB (eds). Brussel, 2006; pp 1-35.

136. Berkman LF, Glass T, Brissette I, et al. From social integration to health: Durkheim in the new millennium. Soc Sci Med 2000; 51(6): 843-857.

137. Chronic Disease Alliance. A unified prevention approach. Chronic Disease Alliance, June 2010.

138. Capewell S, Ford ES, Croft JB, et al. Cardiovascular risk factor trends and potential for reducing coronary heart disease mortality in the United States of America. Bull World Health Organ 2010; 88(2): 120-130.

139. Yusuf S, Pais P, Afzal R, et al. Effects of a polypill (Polycap) on risk factors in middle-aged individuals without cardiovascular disease (TIPS): a phase II, double-blind, randomised trial. Lancet 2009; 373(9672): 1341-1351.

140. Dabhadkar KC, Kulshreshtha A, Ali MK, et al. Prospects for a cardiovascular disease prevention polypill. Annu Rev Public Health 2011; 32: 23-38.

141. Malekzadeh F, Marshall T, Pourshams A, et al. A pilot double-blind randomised placebo-controlled trial of the effects of fixed-dose combination therapy ('polypill') on cardiovascular risk factors. Int J Clin Pract 2010; 64(9): 1220-1227.

142. Rodgers A, Patel A, Berwanger O, et al. An international randomised placebo-controlled trial of a fourcomponent combination pill ('polypill') in people with raised cardiovascular risk. PLoS One 2011; 6(5): e19857.

143. Cooney MT, Dudina A, Whincup P, et al. Re-evaluating the Rose approach: comparative benefits of the population and high-risk preventive strategies. Eur $J$ Cardiovasc Prev Rehabil 2009; 16(5): 541-549. 